\title{
HIGH-ADHESION UNLAYERED FILMS: PHYSICAL AND TECHNOLOGICAL BASIS OF THEIR PRODUCTION
}

\author{
V.F. Bashev*, S.I. Ryabtsev \\ Oles Honchar Dnipro National University, Dnipro, Ukraine \\ *e-mail: bashev_vf@ukr.net
}

\begin{abstract}
Using the modernized three-electrode ion-plasma sputtering method, high-adhesion Cu-films without underlayer were obtained. Films were deposited on glass-ceramic (sitall) substrates. The film thickness was $\sim 500 \mathrm{~nm}$. In this case, the calculated cooling rate reached $\sim 10^{12}-10^{14} \mathrm{~K} / \mathrm{s}$. The adhesion properties of $\mathrm{Cu}$ films were investigated by the standard method of mechanical separation of the film from the substrate the "fungus" method. It is established that such film adhesion is more than 20 MPa. It is determined that the obtained high adhesion depends on bias potential value. Using these $\mathrm{Cu}$ films in strip resonators without a sublayer makes it possible to increase their Q-factor by 1.5-1.7 times and thereby significantly reduce the resulting operating noise.
\end{abstract}

Keywords: thin film, ion-plasma sputtering, adhesion, bias potential.

Received 12.10.2020; Received in revised form 21.11.2020; Accepted 02.12.2020

\section{Introduction}

The adhesion of films to dielectric substrates determines the quality of such important microelectronic products as microcircuits, strip resonators, and switching conductive layers. The high electrical conductivity of metals $\mathrm{Cu}, \mathrm{Ag}, \mathrm{Au}$ is widely used in the production of the above products with their help. However, these metals have unsatisfactory adhesion to dielectric substrates made of sitall, polycor, and quartz at the level of 1.5-2 MPa [1].

To ensure the effective use of films made of these metals, one usually resorts to preliminary deposition of adhesion sublayers of $\mathrm{Cr}$, $\mathrm{V}$ or nichrome on substrates, which have significantly lower values of electrical conductivity, but ensure the adhesion of films of noble metals at a level of $\sim 20 \mathrm{MPa}$. The negative effect of these sublayers is especially pronounced when using such two-layer films in microwave technology at frequencies above $10 \mathrm{GHz}$ due to the emerging skin effect, which is accompanied by the displacement of the high-frequency wave passing in the conducting layer towards the sublayer to the depth $L$ [2]

$$
L \sim\left(T / 2 \mu_{0} \mu \lambda\right)^{-1 / 2}
$$

where $T$ is alternating current period; $\lambda$ is specific electrical conductivity; $\mu_{0}$ and $\mu$ are respectively the magnetic constant and magnetic permeability of the medium.

The physical reason for the skin effect when an alternating current flow through a conductor is the appearance of an electric induction field always directed so that it increases the current at the periphery of the conductor and decreases it in its central part.

As a result, the current density decreases with depth, that is, the current flows practically in the near-surface layer of the metal. Thus, the wave movement at ultrahigh frequencies occurs under conditions that are nonequivalent from the point of view of electrical conductivity, which leads to a deterioration in the Q-factor of the resonators, since the high conductivity of these metals is practically not used in this case. Since in modern microwave technologies there is a persistent tendency to an increase in operating frequencies, the resulting skin effect will play an ever-increasing negative role.

It is known that the deposition of films on a glass-ceramic substrate by the method of three-electrode ion-plasma sputtering simultaneously with the use of the bias potential on the substrate leads to an increase in adhesion [3-8].

In this work, from a physical point of view the reasons for unsatisfactory adhesion are considered, as well as the technology and modes of deposition of copper films with high adhesion on sitall substrates without the use of an underlayer are proposed. 


\section{Experimental procedure}

The objects of study were $\mathrm{Cu}$ films. The deposition of the films was carried out simultaneously on a glass ceramic sitall-substrate by the method of three-electrode ion-plasma sputtering with using a bias potential the substrate [5-8].

For this purpose, the preliminary ionic treatment of the substrate surface was carried out, and then parallel to the ion flow, the flow of condensed copper atoms was connected for 1-2 minutes to displace the molecules of residual gases from the condensation zone completely. Adhesion was measured by the standard method of peeling off the film from the substrate with the determination of the peel load and the area of the film [9].

\section{Results and discussion}

It is known that the reason for the unsatisfactory adhesion of copper to substrates is a layer of oxides based on gases of the residual atmosphere, the atoms of which naturally settle on the surface of the substrate under conditions of an applied working pressure $\left(10^{-3} \mathrm{~Pa}\right)$ at 3-electrode ion-plasma sputtering. Therefore, at the initial stage of deposition, when the first atoms of the sputtered metal $(\mathrm{Cu})$ fly up to the substrate, due to this layer, the formation of short-range "substrate-copper" bonds is blocked. Although the binding energy of gas atoms to the substrate is much lower than that of copper atoms, it is nevertheless sufficient so that condensing metal atoms could not destroy it in a short period of time. According to $[10,11]$, the binding energy of the oxygen molecule to the substrate is significantly higher than $0.15 \mathrm{eV}$; therefore, to clean the surface of the substrate from the oxide layer, it is necessary to raise the substrate temperature above $1600 \mathrm{~K}$, which is unrealistic from the technological point of view. Another method for cleaning the surfaces of substrates is the implementation of an ultra-high vacuum (pressure below $1.3 \cdot 10^{-10} \mathrm{~Pa}$ ) in the working volume, which also presents a great technological complexity in industrial conditions. The most effective method for cleaning substrates is bombarding its surface with argon ions (ionic surface treatment); however, even in this case, the time-separated ion treatment and sputtering process does not provide the necessary destruction of the gas layer on the surface, since even in a short time of moving the substrate from the cleaning zone to of the spraying zone, a gas "shell" has time to form on its surface. To avoid this, we developed a technology for cleaning the surface immediately before the spraying process. For this purpose, it was proposed to carry out ionic treatment of the surface (3-5 min).

And then, without stopping the action of the ion flow on the substrate, simultaneously for (1-2 $\mathrm{min})$, the deposition with displacement is carried out. That is, in this case, there is a condensation of copper atoms with a simultaneous bombardment of the surface with argon ions, which are accelerated by a potential $(-100 \mathrm{~V})$. In this process, the value of the kinetic energy of argon ions is of great importance: it must be sufficient for the destruction of the gas adsorption film, but insufficient for the implantation of argon ions into the substrate and into the primary layers of copper, creating microbubbles in them. Such potential, according to [4], is a bias one of $(-100 \mathrm{~V})$.

At higher or lower values of the potential, the adhesion of the sublayer copper film to the substrate decreases by a factor of tens (Fig. 1).

This bias potential increases the adhesion of the copper film to more than 22 MPa. It was also found experimentally that the adhesion of a copper film also depends on the density of the ion flux, which in turn determines the current density. Thus, at 
a current density of more than $200 \mathrm{~A} / \mathrm{m}^{2}$, the ion flux density reaches saturation, as evidenced by a plateau on the curve (Fig. 2).

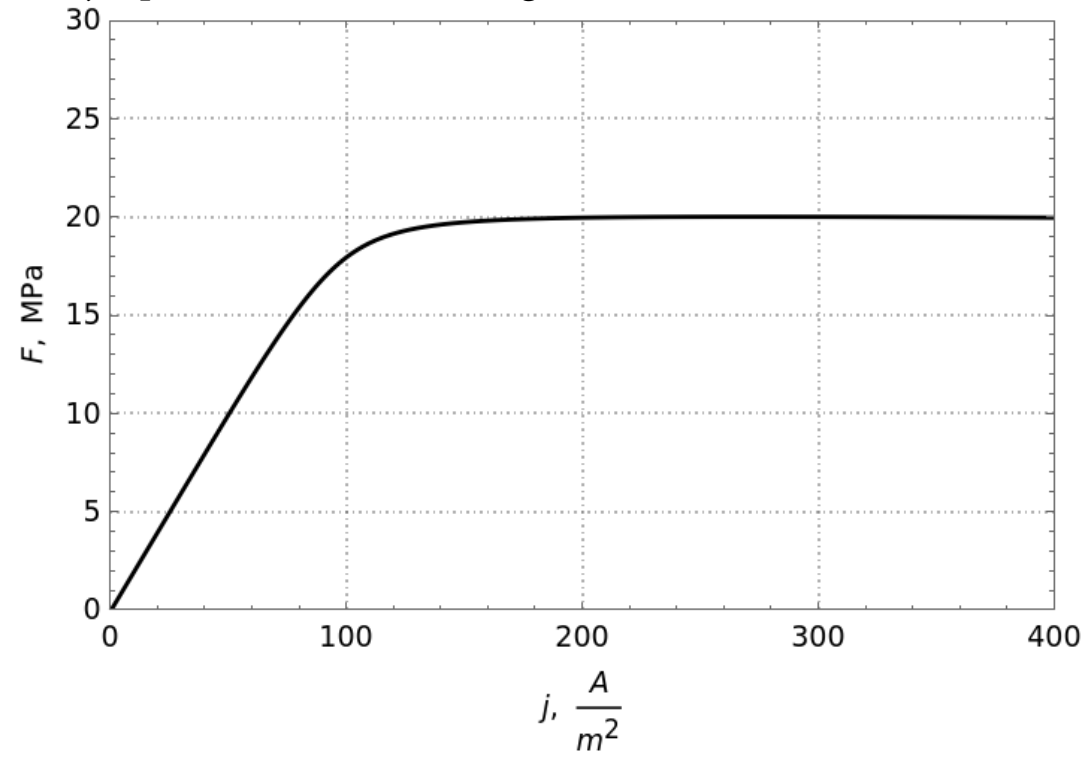

Fig. 1. Dependence of the adhesion of copper films without an underlayer on the ion current density at a bias potential $(-100 \mathrm{~V})$.

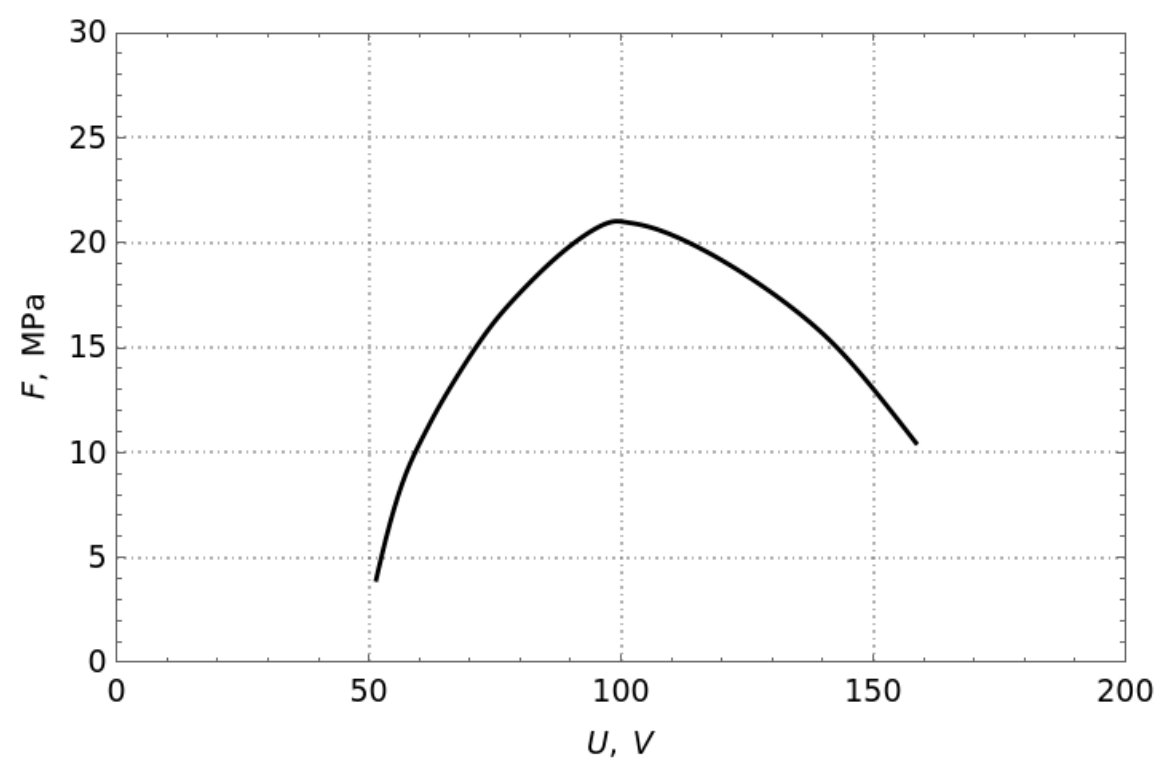

Fig. 2. Dependence of the adhesion value of copper films without an underlayer on the bias potential on sitall substrates.

This current density is optimal for ionic processing and for deposition with displacement. At the final stage of the process, when the stationarity of the flow of copper atoms is achieved and gas atoms are almost completely displaced from the condensation zone, the need for an ion flow disappears. And after (1-2 min) deposition with the offset, the deposition process can be continued without applying this potential to the substrate. 


\section{Conclusions}

In conclusion, it should be noted that the use of copper coatings in microwave film resonators without using a sublayer made it possible to increase their Q-factor by 1.5-1.7 times and thereby significantly reduce the resulting operating noise.

\section{References}

1. Kostrzhitskiy, A.I. Bahatokomponentni vakuumni pokryttya / A.I. Kostrzhitskiy, O.V. Lebedyns'kyy. - Moskva: Mashinostroyeniye, 1987. - 208 p.

2. Kuz'michev, V.E. Zakony ta formuly fizyky. Dovidnyk / V.E. Kuz'michev. Kyyiv: Naukova dumka, 1989. - 864 p.

3. Ryabtsev, S.I. Structure and properties of ion-plasma-deposited films of $\mathrm{Fe}-$ (Ag,Bi) alloys / S.I. Ryabtsev // Phys. Met. Metallogr. - 2009. - Vol. 108, No. 3. - P. 226 -231 .

4. Bashev, V.F. Effect of nonequilibrium vapor deposition on phase composition and properties of Fe-Mg films / V.F. Bashev, O.E. Beletskaya, Z.V. Balyuk, S.I. Ryabtsev // Physics of Metals and Metallography. -2003. - Vol. 96, Issue 1. -P. 72 - 74.

5. Bashev, V.F. Physical properties and structure of vapor-quenched immiscible alloys / V.F. Bashev, N.A. Kutseva, A.I. Kushnerov, et al. /Journal of Physics and Electronics. - 2018. - Vol. 26(1). - P. 45 - 52.

6. Ryabtsev, S. Structure and Physical Properties of Ni Films in Metastable States / S. Ryabtsev, P. Gusevik, V. Bashev, F. Dotsenko / J. Mater. Sci. Eng. -2012. - Vol. A2, No. 9. - P. $648-653$.

7. Dotsenko, F.F. Physical preconditions of non-equilibrium state formation and estimation of deposited alloys composition / F.F. Dotsenko, V.F. Bashev / Visnyk Dnipropetrovs'koho Universytetu. Physics. Radioelectronics. - 2001. - Issue 7. - P. 8 17.

8. Torianik, I.N. Physical formation of multiple, composite (multiphase) coatings obtained by ion-plasma methods / I.N. Torianik, U.S. Nyenchenko, A.D. Pogrebnjak, O.V. Sobol', S.S. Grankin, P.V. Turbin, S.S. Bitimanova // Physical Surface Engineering. - 2014. - Vol. 12, No. 1. - P. $100-113$.

9. Lunev, V.M. Adhesion characteristics of coatings and methods of their measurement / V.M. Lunev, O.V. Nemashkalo // Physical Surface Engineering. - 2010. Vol. 8, No. 1. - P. 64. -71 .

10. Uils, Z. Fizika poverkhnosti: kolebatel'naya spektroskopiya adsorbatov / Z. Uils, D. N'yus, L. Dobrzhinskiy. - Moskva: Mir, 1984. - 248 p.

11. Martin, P.M. Handbook of deposition technologies for films and coatings. 3rd edition. - Elsevier, 2010. - 912 p. 